\title{
Living in the Present: Rethinking the Paradox of Suspense through Videogames
}

\author{
Dr Paul Atkinson \\ Monash University \\ Room S718 Menzies \\ Building, Clayton \\ 3800 \\ Telephone: 99047026 \\ paul.atkinson@monash.edu \\ Farzad Parsayi \\ Monash University \\ Menzies Building, \\ Clayton 3800 \\ farzad.parsayi@monash.edu
}

\section{Keywords}

Suspense, preparedness, narrative uncertainty, haptic preparedness

In the study of film, Nöel Carroll (2001) coined the term the "paradox of suspense" to refer to a situation in which rewatching a film continues to invoke suspenseful feelings. According to the paradox, the tension associated with anticipation and uncertainty persists even though the spectator definitely knows what will happen (Carroll 2001). Many of the articles on the paradox and suspense examine the narrative events shaping spectator or player knowledge (Branigan 1992; Gerrig 1997; Ortony, Clore, and Collins 1988; Prieto-Pablos 1998; Smuts 2008; Yanal 1996), however, this paper takes a slightly different approach by addressing factors that contribute to the feeling of suspense irrespective of the awareness of specific narrative events. By examining videogames, we also shift the frame of reference from narration to gameplay and the way players prepare for suspenseful events. We argue that videogames require a particular attitude manifest in the gameplay that continues to foster suspense even in the replaying of a game.

Suspense is a broad term that relates as much to the player's experience of time as it does to the narrative features of a game. It derives from the fact that narrative events are always embedded within the broader category of lived experience and the particular constitution of the present (Ricoeur 1980); a present that constantly changes depending on what the player is attending to. In addition to the distant future of narrative events, suspense derives from the immediate future of a game and the way the medium engages a broad range of senses in order to invoke the feeling of presence (Lombard and Ditton 1997). The suspenseful feelings of anxiety and apprehension are integrated into the overall presentness of gameplay, including touch and the kinaesthetic feelings (Tavinor 2009). These feelings are continually cultivated through controller feedback and the way the hand anticipates what is happening onscreen. Suspense is just one facet of a broader feeling of presentness and the preparedness to act.

Feelings of suspense are felt in the player's present but are also cultivated over an extended period, which is partly determined by how the player controls the pace of the gameplay. The player has some control over the duration of events and the period leading up to a future event, which is evident in the capacity to pause a game, look or run away from a situation, or even to remain outside of the action for long periods in open world games. The videogame player has a greater ability to change screen content than a film spectator, and therefore can somewhat moderate their response to suspenseful events, which is manifest as a "dynamic between being in control and out of control" (Tanya Krzywinska quoted in Perron 2011, 9). As suspense is 
often associated with a lack of control over unwanted future events, Smuts and Frome (2004) argue that cut scenes constitute the only time in the game in which the player feels suspense. The argument has some validity but does not sufficiently take into account the suspense associated with the requirement to act. In many respects, the cut scene represents a time without suspense because the player does not have to respond to imminent events. As Richard Rouse III notes, a "game's most immersive device, the constant fear of death and setback that keep players supremely focused on the moment, is not at all present during a cut-scene" (2009, 22). Furthermore, for most suspenseful games, the character could die at any moment and not only in relation to specific predetermined events; something that is greatly amplified in games with permadeath.

Central to the examination of suspense in videogames is how a player manages the immediate future of the game, in other words, the way that they prepare for a future action or event. This condition of preparedness is implicit in a range of states from the foreshadowing of narrative events to hypervigilance, where the player is extremely attentive to all onscreen movements as possible threats; something which is not a feature of cinema spectatorship. Preparedness is central to the analysis of videogames because it is strongly linked to the imminent actions and perceptions of the player, and draws upon the phenomenological tradition in which perception is strongly linked to the body's engagement with the world (Merleau-Ponty 1964). From this perspective, actions and perceptions simultaneously modulate the feeling of suspense. For example, the inability to control the viewpoint or restrictions on action could relieve suspense under certain conditions. Habel and Kooyman (2014) argue that in Dead Space 2 restriction on movement and viewpoint in the ventilation shafts "allows a brief respite from action," and that the feeling of suspense derives from anticipating leaving the shaft (8). Staying in the shaft could reduce suspense because the player knows that they cannot be attacked if they remain there, however, suspense increases as soon as the player prepares the leave the confined space - they know they must act. In a videogame, preparing to act is strongly linked to the visibility of the storyworld. In a suspense game, the threat is often invisible or just outside the field of view, ensuring that the player is always vigilant; a state that contributes to the feeling of suspense. As soon as the player engages in action the feeling changes. The visibility of the storyworld can be restricted by a variety of means - the choice of viewpoint, limits on how much the body can move, loss of peripheral vision (in FPS games), etc. - each of which modulates the feeling of suspense.

In summary, we analyse the paradox of suspense through the idea of player preparedness. This involves investigating the affordances of videogames from a phenomenological perspective, where the presentness of experience constantly informs the imagining of future events. We suggest that vigilance and the preparedness to act are key constituents of suspense that operate independently but, nevertheless, complement the narrative construction of suspense.

\section{Reference List}

Branigan, Edward. 1992. Narrative Comprehension and Film. London: Routledge.

Carr, David. 1986. Time, Narrative, and History. Bloomington: Indiana University Press.

Carroll, Noël. 2001. Beyond Aesthetics: Philosophical Essays. Cambridge: Cambridge University Press.

Gerrig, Richard J. 1997. "Is There a Paradox of Suspense? A Reply to Yanal." British Journal of Aesthetics 37, no. 2: 168-74.

Habel, Chad and Ben Kooyman. 2014. "Agency mechanics: gameplay design in survival horror video games.” Digital Creativity 25, no. 1: 1-14. DOI: 10.1080/14626268.2013.776971

Lombard, Martin and Theresa Ditton. 1997. "At the Heart of It All: The Concept of Presence." Journal of Computer-Mediated Communication 3, no. 2. DOI: 10.1111/j.1083- 
6101.1997.tb00072.x

Merleau-Ponty, Maurice. 1964. The Primacy of Perception. Evanston: Northwestern University Press.

Ortony, Andrew, Gerald L. Clore and Allan Collins. 1988. The Cognitive Structure of Emotions. New York: Cambridge University Press.

Perron, Bernard. 2012. Silent Hill: The Terror Engine. University of Michigan Press. DOI: 10.3998/lvg.11053908.0001.001.

Prieto-Pablos, Juan A. 1998. "The Paradox of Suspense." Poetics 26, no. 2: 99-113. DOI: 10.1016/S0304-422X(98)00014-X.

Rouse III, Richard. 2009. "Match Made in Hell: The Inevitable Success of the Horror Genre in Video Games." In Horror Video Games: Essays on the Fusion of Fear and Play, edited by Bernard Perron, 15-45. Jefferson, NC: McFarland.

Ricoeur, Paul. 1980. “Narrative Time.” Critical Inquiry 7, no. 1: 169-90.

Smuts, Aaron. 2008. "The desire-frustration theory of suspense." Journal of Aesthetics and Art Criticism 66, no. 3: 281-91.

Smuts, Aaron, and Jonathon Frome. 2004. "Helpless Spectators: Generating Suspense in Videogames and Film.” Text Technology 1, no. 1: 13-34.

Tavinor, Grant. 2009. The Art of Videogames. Chichester: Wiley-Blackwell.

Yanal, Robert. 1996. "The Paradox of Suspense." The British Journal of Aesthetics 36, no. 2 : 146-58. DOI: 10.1093/bjaesthetics/36.2.146. 